\title{
ARRANJOS COM DIFERENTES ESPAÇAMENTOS PARA CULTIVARES DECUMBENTES PRECOCES DE AMENDOIM
}

Jair Heuert ${ }^{1}$; Taís de Moraes Falleiro Suassuna ${ }^{2}$; Kennedy Brunno de Brito Martins³; Washington da Conceição Gonçalves ${ }^{4}$

'Embrapa, Santo Antônio de Goiás-GO, jairheuert@embrapa.br; ${ }^{2}$ Pesquisadora da Embrapa, Santo Antônio de Goiás-GO; ${ }^{3}$ Acadêmico de Biologia, Faculdade Araguaia, Goiânia-GO; ${ }^{4}$ Acadêmico de Biologia, Faculdade Araguaia, Goiânia-GO

RESUMO: O cultivo de amendoim tipo "runner" no Brasil é recente, demandando mais estudos sobre espaçamentos e arranjos de semeadura para novos genótipos que tem um crescimento mais determinado e produção de vagens mais próxima da haste central da planta. Para este estudo a linhagem 13-413 OL foi usada no delineamento de blocos casualizados com sete repetições e três tratamentos: T1: Linha simples de $90 \mathrm{~cm}$; T2: Linha dupla de $73 \mathrm{~cm}$ x $17 \mathrm{~cm} \mathrm{e} \mathrm{T3:} \mathrm{linha} \mathrm{simples} \mathrm{de} 70$ $\mathrm{cm}$. O ensaio foi instalado na área experimental da Embrapa em Santo Antônio de Goiás-GO. Cada parcela foi composta por quatro linhas, onde as duas linhas centrais foram avaliadas. Os resultados mostraram que no espaçamento $90 \mathrm{~cm}$ a produtividade foi de $3.668,5 \mathrm{~kg} \mathrm{ha}^{-1}$, no espaçamento de 73 cm x 17 cm obteve-se 4.080,2 $\mathrm{kg} \mathrm{ha}^{-1}$ e no espaçamento de $70 \mathrm{~cm}$ obteve-se $4.768,1 \mathrm{~kg} \mathrm{ha}^{-1}$.

Palavra chaves: Arachishypogaea L., configuração de semeadura, população de plantas, espaçamento entre linhas.

\section{INTRODUÇÃO}

A cultura de amendoim tem conquistado cada vez mais a sua importância, atendendo o mercado interno e apresenta boas perspectivas de aumento de participação no mercado externo, devido à valorização do grão brasileiro. Com demanda crescente, torna-se importante intensificar pesquisas, visando aumentar os conhecimentos técnico-científicos que possibilitem ganhos de produtividade por área(BULGARELLI,2008).

$\mathrm{Na}$ Argentina amendoim é cultivado em linhas simples no espaçamento de $70 \mathrm{~cm}$ (GAMBA et. al., 2009). O espaçamento predominante no Brasil é baseado naquele utilizado nos Estados Unidos, com linhas simples espaçadas de $90 \mathrm{~cm}$ oulinhas duplas espaçadas de $73 \mathrm{~cm}$ x $17 \mathrm{~cm}$. Há questionamentos por parte de alguns agricultoressobre a possibilidade de redução do espaçamento entre linhas e sobre diferentes arranjos espaciais de plantas para as novas cultivares brasileiras. Estes novos genótipos aparentemente possuem características morfofisiológicas de crescimento mais determinado, de alto potencial produtivo, com precocidade e uma produção de vagens mais concentrada próxima à haste principal (HEUERT, 2017). 
16 e 17 de agosto de 2018, centro de convenções da FCAV/UNESP - Câmpus de Jaboticabal, SP

ROMANINI JUNIOR (2007) observou que a produtividade de vagens da cultivar 'Runner IAC 886', em arranjo de linhas duplas (73 cm x $17 \mathrm{~cm}$ ) obteve produtividade de $11,1 \%$ superior em comparação com o espaçamento linha simples de $90 \mathrm{~cm}$.

Em outro trabalho (HEUERT et al., 2017), usando a linhagem 13-413 OLobteve 11,04 \% a mais na produtividade quando comparou o arranjo de linha dupla $(73 \mathrm{~cm} \times 17 \mathrm{~cm})$ com linha simples de $90 \mathrm{~cm}$. A redução de $90 \mathrm{~cm}$ para $75 \mathrm{~cm}$ houve um ganho de 26,55\% na produtividade devido a uma melhor otimização da área.

O presente trabalho teve por objetivo avaliar os efeitos do espaçamento de plantas sobre a produtividade de amendoim na linhagem 13-413 OL em áreas com colheita mecanizada.

\section{MATERIAIS E MÉTODOS}

O experimento foi instalado na safra 2017/18, na área experimental da Embrapa no município de Santo Antônio de Goiás-GO. A linhagem 13-413 OL, de crescimento determinado, foi semeada manualmente no dia 05 de janeiro de 2018. Todos os tratos culturais seguiram as recomendações para a cultura, resultando em desenvolvimento adequado das plantas.
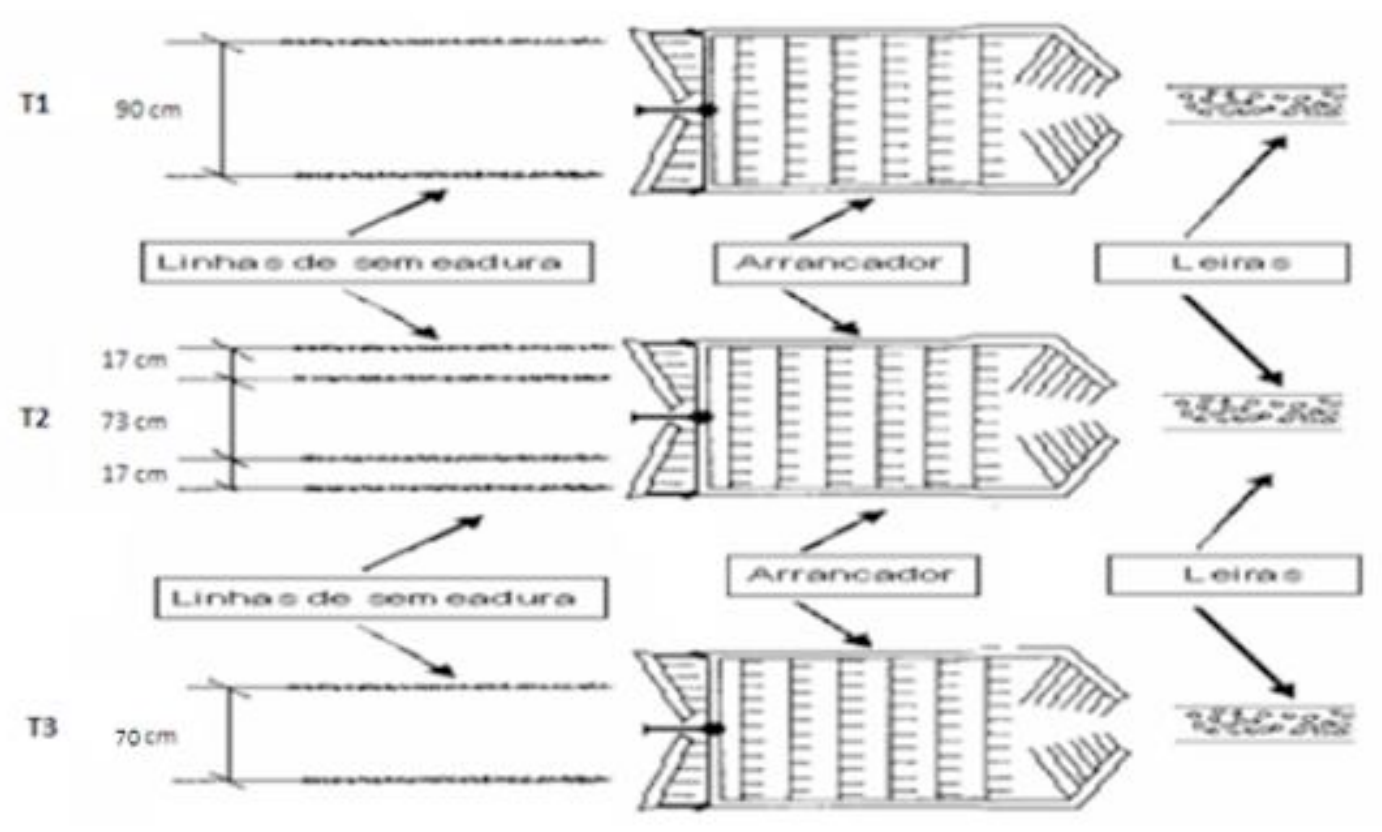

Figura 1. Esquema ilustrativo das linhas de semeadura dos arranjos de semeadura em linhas simples (T1-90 cm; T3-70 cm) e duplas (T2-73 cm x17 cm).

O delineamento experimental utilizado foi o de blocos completos com sete repetições, as parcelas eram compostas por quatro linhas de três metros de comprimento. Os tratamentos foram os seguintes: T1) amendoim semeado em linhas simples, $90 \mathrm{~cm}$ entre linhas e 20 sementes por metro linear, com uma área útil $5,4 \mathrm{~m}^{2}$; T2) amendoim semeado em fileiras duplas, com duas linhas 
16 e 17 de agosto de 2018, centro de convenções da FCAV/UNESP - Câmpus de Jaboticabal, SP

distanciadas a $17 \mathrm{~cm}$, mantendo-se a distância de $73 \mathrm{~cm}$ entre as linhas, utilizando 20 sementes por metro linear divididas nas duas linhas com área útil de parcela de 5,4 $\mathrm{m}^{2}$ (ROMANINI JUNIOR, 2007) e T3) amendoim semeado em fileiras simples com espaçamento entre linhas de $70 \mathrm{~cm}$, utilizando 15,5 sementes por metro linear ocupando uma área de parcela útil de 4,2 $\mathrm{m}^{2}$.

A inversão das parcelas foi mecanizada, usando um arrancador de duas linhas da marca MIAC, modelo C200. Após o período de secagem no campo, foram colhidas às duas linhas centrais de cada parcela para determinação da produtividade. Análise de variância foi realizada usando o programa SISVAR 5.6. O teste de médias foi empregado ScootKnott, a 5\% de probabilidade.

\section{RESULTADOS E DISCUSSÕES}

A média do ensaio ficou $4,172,2 \mathrm{Kg} / \mathrm{ha}^{-1}$. No espaçamento de linha simples de $90 \mathrm{~cm}$ a produtividade ficou em $3.668,5 \mathrm{Kg} / \mathrm{ha}^{-1}$. No arranjo de linha dupla $(73 \mathrm{~cm} \times 17 \mathrm{~cm})$ houve um incremento de $11,22 \%$ em relação ao T1. Quando se utilizou o arranjo de plantio em linhas simples com espaçamento entre as mesmas de $70 \mathrm{~cm}$ (T3), verificou-se que a produtividade aumentou 29,97\%. Possivelmente, neste tratamento (T3) houve uma melhor otimização da área, devido as linhas terem uma distância menor entre si. Um hectarecom linhas espaçadas a $90 \mathrm{~cm}$, possui $11.111,1$ metros lineares de produção, já num espaçamento de $70 \mathrm{~cm}$ possui $14.285,7$ metros lineares de produção. No espaçamento de $70 \mathrm{~cm}$ teremos $28,57 \%$ de ganho de área produtiva em comparação ao espaçamento de $90 \mathrm{~cm}$, assemelhando-se a porcentagem de ganho obtido do T1 em comparação ao T3. Entretanto, percebeu-se que neste tratamento $(70 \mathrm{~cm})$ houve dificuldade na inversão com o arrancador.

Tabela 1. Produtividade de amendoim em diferentes espaçamentos de cultivo.

\begin{tabular}{cccccc}
\hline \multirow{2}{*}{ Espaçamento (cm) } & \multicolumn{3}{c}{ Número de plantas } & \multicolumn{3}{c}{ Produtividade } \\
\cline { 2 - 6 } & metro & Hectare & $\left(\mathbf{k g} / \mathbf{h a}^{-1}\right)$ & Sacas/alqueire & Incremento (\%) \\
\hline $90 \mathrm{~cm}$ & 20 & 222.000 & $3.668,5 \mathrm{c}$ & 355,1 & - \\
$73 \mathrm{~cm} \mathrm{X} \mathrm{17} \mathrm{cm}$ & $10 \times 10$ & 222.000 & $4.080,2 \mathrm{~b}$ & 394,9 & $11,22 \%$ \\
$70 \mathrm{~cm}$ & 15,5 & 221.500 & $4.768,1 \mathrm{a}$ & 461,5 & $29,97 \%$ \\
\hline Média & - & - & $4.172,2$ & - & - \\
\hline CV (\%) & - & - & 7,66 & - & - \\
\hline F & - & - & 21,1 & - & -
\end{tabular}

Médias seguidas de mesma minúscula na coluna não diferem entre si pelo teste de Scott Knott $(\mathrm{p} \geq 0,05) \cdot{ }^{(1)} \mathrm{CV}$ : Coeficiente de Variação; ${ }^{(2)}$ *significativo a $1 \%$ de probabilidade pelo teste $\mathrm{F}$

A linhagem 13-413 OL se adapta bem aos diferentes sistemas adotados no Brasil para o cultivo de amendoim. Verificou-se também que é possível semeá-la em espaçamento entre fileiras menor do que $90 \mathrm{~cm}$, provavelmente devido ao seu crescimento mais determinado e produção de vagens mais próxima da haste central da planta. A redução no espaçamento é viável desde que haja 
variedades adequadas e disponibilidade de arrancadores/invertedores ajustados para um espaçamento menor do que $90 \mathrm{~cm}$. Mais estudos com genótipos de amendoim decumbentes precoces poderão fornecer informações importantes sobre mudanças nas características morfofisiológicas, auxiliando tanto no manejo cultural quanto no desenvolvimento de novas cultivares de amendoim "Runner" precoces.

\section{CONCLUSÃO}

A linhagem 13-413 OL se adapta aos três tipos de arranjos de semeadura, tanto para os de linhas simples (90 cm e $70 \mathrm{~cm})$ e de linhas duplas $(73 \mathrm{x} 17 \mathrm{~cm})$.

Também foi observado que a redução de $90 \mathrm{~cm}$ entre linhas para $70 \mathrm{~cm}$, há um melhor aproveitamento de espaço, com isso permite um ganho na produtividade por área.

No arranjo de linha dupla, ocorre uma melhor distribuição de plantas e com isso ocorre um aumento na produtividade em comparação a linha simples de $90 \mathrm{~cm}$.

\section{REFERENCIAS BIBLIOGRÁFICAS}

BULGARELLI, E.M.B. Caracterização de variedades de amendoim cultivadas em diferentes populações - Dissertação (mestrado) - Universidade Estadual Paulista, Faculdade de Ciências Agrárias e Veterinárias, Jaboticabal, 2008.

HEUERT, J; SOUZA, A.C.A. de; OLIVEIRA, B. N.; Zerbato, C.; COSTA, L.C.; MARTINS, K.B. B.; SUASSUNA, T.M.F.; RIBEIRO, T.C.N.; RIBEIRO, R.P. e SOFIATTI, V.. Arranjo de semeadura para cultivares decumbentes precoces de amendoim. In:Anais do encontro sobre a cultura do amendoim, 2017, Resumos... Campinas, GALOÁ, 2018. Disponível em: $<$ https://proceedings.science/encontro-amendoim-2017/trabalhos/arranjo-de-semeadura-paracultivares-decumbentes-precoces-de-amendoim> Acesso em: 01 jul. 2018.

GAMBA, J.M; PEDELINI, R. Evaluacion del rendimento y calidad de três cultivares de mani. Granoleico, ASEM 484 INTA y ASEM 485 INTA. Xxiv Jornada Nacional de Maní. General Gabrera, Cordoba - Argentina, 2009.

ROMANINI JUNIOR, A. Influência do espaçamento de plantas no crescimento, produtividade e rendimento do amendoim rasteiro, cultivar Runner IAC 886, Dissertação (mestrado em agronomia Produção Vegetal). Universidade Estadual Paulista, Faculdade de Ciências Agrárias e Veterinárias, 2007. 